\title{
Cell-specific Roles of Glucokinase in Glucose Homeostasis
}

\author{
Catherine Postic, Masakazu Shiota, and Mark A. Magnuson \\ Department of Molecular Physiology and Biophysics, \\ Vanderbilt University School of Medicine. Nashville, Tennessee 37232
}

\begin{abstract}
Mutations in the glucokinase (GK) gene cause two different diseases of blood glucose regulation: maturity onset diabetes of the young, type 2 (MODY-2) and persistent hyperinsulinemic hypoglycemia of infancy (PHHI). To gain further understanding of the pathophysiology of these disorders, we have used both transgenic and gene-targeting strategies to explore the relationship between GK gene expression in specific tissues and the blood glucose concentration. These studies, which have included the use of a Cre/loxP gene-targeting strategy to perform both pancreatic $\beta$-cell-and hepatocyte-specific knockouts of GK, clearly demonstrate multiple, cell-specific roles for this hexokinase that, together, contribute to the maintainance of euglycemia. In the pancreatic $\beta$ cell, GK functions as the glucose sensor, determining the threshold for insulin secretion. Mice lacking GK in the pancreatic $\beta$ cell die within 3 days of birth of profound hyperglycemia. In the liver, GK facilitates hepatic glucose uptake during hyperglycemia and is essential for the appropriate regulation of a network of glucose-responsive genes. While mice lacking hepatic GK are viable, and are only mildly hyperglycemic when fasted, they also have impaired insulin secretion in response to hyperglycemia. The mechanisms that enable hepatic GK to affect $\beta$-cell function are not yet understood. Thus, the hyperglycemia that occurs in MODY- 2 is due to impaired GK function in both the liver and pancreatic $\beta$ cell, although the defect in $\beta$-cell function is clearly more dominant. Whether defects in GK gene expression also impair glucose sensing by neurons in the brain or enteroendocrine cells in gut, two other sites known to express GK, remains to be determined. Moreover, whether the pathophysiology of PHHI also involves multitissue dysfunction remains to be explored.
\end{abstract}

\section{Kinetic Behavior and Tissue-specific Functions of Glucokinase}

The first step in glycolysis in mammals is catalyzed by four different hexokinases. Hexokinases I-III are cach about $100 \mathrm{kDa}$ in size, have relatively high affinities for several different hexose substrates, and are inhibited by physiological concentrations of glucose-6-phosphate (G6P) (Wilson, 1995). In contrast, hexokinase IV, more commonly known as glucokinase (GK), is about half the molecular mass, has a $\mathrm{K}_{\mathrm{cat}} \mathrm{S}_{0.5}$ that is similar to the blood glucose concentration, displays sigmoidal kinetics, and is not significantly affected by physiological concentrations of G6P. These unique kinetic features of GK have long been thought to be of key functional significance in the liver and pancreatic $\beta$ cell, two sites where 
the enzyme has been known for years to be expressed (Weinhouse, 1976; Meglasson and Matschinsky, 1983). The predicted functional importance of this enzyme in these cell types has led to intensive investigation, both in humans and in animal model systems, to understand the role of GK in determining the setpoint for the blood glucose concentration. These studies have led to the discovery that mutations in GK cause two different glycemic disorders in humans, clearly demonstrating the pivotal role of this enzyme in maintaining euglycemia.

In the pancreatic $\beta$ cell, GK is a key component of the glucose-sensing machinery (Matschinsky et al., 1998). The phosphorylation of glucose within $\beta$ cells is tightly coupled to insulin secretion. The unique kinetics of GK underlie the ability of these cells to sense and respond to fluctuations in the plasma glucose concentration. Because of this, GK is considered the "glucose sensor" of the $\beta$ cell, a term coined by Matschinsky (Meglasson and Matschinsky, 1984). Modeling of changes in GK activity, as well as studies of the effects of graded increases in the enzyme, have established that glucose phosphorylation is the key point of control for glycolytic flux in the $\beta$ cell (Liang et al., 1992; Wang and Iynedjian, 1997). Consequently, even small changes in GK activity can be physiologically significant, since they directly affect the threshold for glucose-stimulated insulin secretion.

The now-well-established functional principals of how GK contributes to a biochemical sensing mechanism in $\beta$ cells have enabled these cells to be considered a prototype for exploring the mechanisms of glucose sensing in other cell types that exhibit functional changes in response to alterations in the glucose concentration to which they are exposed. For instance, it has long been known that certain cells in both the hypothalamus and gut are also glucose responsive, although the biochemical mechanisms involved remain unknown. In this regard, the identification of GK gene expression in these sites led us to suggest that GK also functions as a glucose sensor in some or all of these cells (Jetton et al., 1994) as it does in the $\beta$ cell. While direct data in support of this notion are only beginning to be generated (Roncero et al., 2000), this remains a plausible hypothesis.

In liver, GK has long been thought to be essential for the unique metabolic functions of this tissue. Indeed, GK was first discovered in the liver over 40 years ago (Grossbard and Schimke, 1966). Studies over the past few years in humans, animal models, and isolated hepatocytes have established that hepatic GK exerts a very strong influence on glucose utilization and glycogen synthesis. Even small changes in the expression of GK in transgenic mice lead to a measurable impact on the blood glucose concentration (Ferre et al., 1996; Hariharan et al., 1997; Niswender et al., 1997b). Moreover, complementary studies in primary hepatocytes have shown that GK overexpression elevates intracellular G6P (Seoane $e t$ 
al., 1996), which triggers an increase in both glycolysis and glycogen synthesis (Aiston et al., 1999).

Metabolic flux in the liver reflects the net activitics of several major pathways. Enzymes in these pathways are regulated largely at the transcriptional level by the metabolism of glucose (Girard, 1997). Genes regulated by glucose - such as L-type pyruvate kinase (L-PK) (Vaulont and Kahn, 1994), $\mathrm{S}_{14}$ (Shih and Towle, 1994), fatty acid synthase (Foufelle et al., 1996), and GLUT2 (Rencurel et al., 1996) - have all been found to contain carbohydrate response elements. While the mechanisms whereby glucose is able to affect transcription of these genes is not very well understood, the essential role that GK plays in enabling glucose to regulate the expression of a network of glucose-responsive genes is evident. Thus, GK is widely thought to play a key role in regulating hepalic glucose metabolism. Indeed, GK gene expression, by determining the regulation of genes involved in fatty acid metabolism, plays an important role in hepatic lipogenesis (Girard, 1997).

\section{Transcriptional and Post-translational Regulation of GK}

Given the vital role of this hexokinase in determining insulin secretion by the cell, glucose uptake by the liver, and in modulating expression of an entire network of hepatic glucose-responsive genes, it is of little surprise that the regulation of GK gene expression is complex. However, two aspects of GK regulation are particularly intriguing and merit discussion. First, the GK gene contains two widely separated and functionally distinct promoters that regulate expression at the transcriptional level. These alternate promoters lead to the production of tissue-specific $\mathrm{GK}$ isoforms that differ in their $\mathrm{N}$-terminal amino acids sequences (Magnuson, 1990). Second, hepatic GK, in addition to being regulated at the level of gene transcription, is regulated at a post-translational level by binding to the GK regulatory protein (GKRP) (Van Schaftingen, 1989).

Cloning and characterization of an $83-\mathrm{kb} \mathrm{P} 1$ clone that contains both promoter regions and all coding sequences of the mouse GK preceded genetic manipulations in mice (Postic et al., 1995). This effort revealed that the 11 exons of the gene span $49 \mathrm{~kb}$, most of which is accounted for by $35 \mathrm{~kb}$ of DNA between exons $1 \beta$ and $1 \mathrm{~L}$. More importantly, the availability of a single, contiguous DNA fragment containing the entire mouse GK gene allowed the generation of transgenic mice with increased gene copy number, as will be described in detail. Sequencing of the mouse GK gene revealed that murine GK is more than 94 percent identical to rat and human GK. Moreover, DNA sequence alignment of the upstream and downstream promoter regions of the mouse, rat, and human genes has revealed many different, evolutionarily conserved regions whose functions remain to be determined. 
The upstream GK promoter initially was thought to be expressed only in pancreatic $\beta$ cells. However, studies have demonstrated GK expression from the upstream promoter in pituitary corticotropes as well as in certain neural/neuroendocrine (NE) cells of the brain and the gut (Hughes et al., 1991; Jetton et al., 1994,1998). All of the regulatory elements necessary for expression in these sites, including $\beta$ cells, appear to be contained within a 294-bp fragment of DNA (Shelton et al., 1992; Jetton et al., 1994,1998). Indeed, a detailed mutational analysis of the upstream promoter has revealed several different classes of regulatory elements within this region (Shelton et al., 1992; Moates, et al., 1996), at least one of which, termed the Pal elements, appears to be unique. Expression of the upstream promoter has, until recently, been thought to be largely constitutive. However, retinoic acid was shown to increase pancreatic GK expression in cultured islets (Cabrera-Valladares et al., 1999). Since the physiological role of retinoic acid in $\beta$-cell function has not been determined, further studies are required to pinpoint the regulatory elements and signal transduction pathways involved. While there have been several efforts to examine the transcriptional regulation of the upstream promoter, the changes observed have been small and thus may have been dismissed as not being significant. However, now that we know that even small changes in GK activity can affect the threshold for insulin secretion, a re-examination of the effects of various hormones and other agents on the expression of GK in the islet has begun. Moreover, given that GK gene expression has been found to occur in a phenotypically diverse set of neu$\mathrm{ral} /$ neuroendocrine cells, further studies of the elements and factors involved in the cell-specific expression of this enzyme likely will provide additional insights.

In liver, GK gene transcription is stimulated by insulin and repressed by glucagon acting via cAMP (lynedjian et al., 1989; Magnuson et al., 1989). Unfortunately, despite extensive efforts using both classical transfection experiments and transgenic mice (Niswender et al., 1997a; Iynedjian, 1998), we continue to have very little knowledge about the cis-acting elements in the hepatic (downstream) GK promoter that are responsible for its cell-specific expression and regulation. Preliminary results of fusion gene studies in transgenic mice suggest that the conserved regions near the transcription start site in hepatocytes are themselves not sufficient for either position-independent expression in liver or regulation by insulin (Postic et al., data not shown). Indeed, given the results of DNAse I hypersensitive site-mapping studies - which have revealed no less than 11 liver-specific, hypersensitive sites in an approximately $50-\mathrm{kb}$ region of the mouse gene - the downstream GK promoter appears to be more complicated in its regulation than many other hepatic genes studied to date (Postic et al., 1995; Moates et al., 1997).

Although mapping regulatory elements in the hepatic GK promoter via a fusion gene approach has been hindered by the apparent size of the regulatory unit 
and the lack of hepatoma cell lines that express this gene, recent work by Foretz et al. (1999) has implicated sterol regulatory element-binding protein-1c (SREBP$1 c)$ as an activator for transcription of hepatic GK in cultured hepatocytes. In this study, SREBP-1c, which belongs to a family of transcription factors involved in cholesterol and fatty acid metabolism (Brown and Golstein, 1997), was suggested to mediate the effect of insulin on hepatic GK gene transcription. However, this notion contrasts with the observation that overexpression of SREBP-1c does not affect the levels of GK mRNA in liver of transgenic animals (Sebastian et al., 2000). Although the reason for this discrepancy is not readily evident, further studies of the role of SREBP-1c in determining hepatic GK expression may help us to understand how the downstream GK promoter is regulated by insulin and other hormones.

The interaction between GK and GKRP in liver affects both activity and subcellular location of the enzyme (Van Schaftingen, 1989; Vandercarmmen and Van Schaftingen, 1990; de la Iglesia et al., 1999; Shiota et al., 1999). By reversibly binding to and inhibiting GK, GKRP is able to affect hepatic glucose usage and probably also the responsiveness and sensitivity of the hepatocytes to changes in glucose concentrations (de la Iglesia et al., 2000). Interestingly, GKRP knockout mice have impaired glucose tolerance and less GK than normal animals with this protein (Farrelly et al., 1999; Grimsby et al., 2000). Thus, binding of GK to GKRP may protect it from degradation, providing a reservoir of protein that can be quickly mobilized after feeding. While further studies are necessary to understand the role that GKRP plays in regulating hepatic GK, we and others have obtained data indicating that GKRP is necessary for the translocation of GK into the nucleus (Shiota et al., 1999; Bosco et al., 2000). Moreover, our studies have shown that GK contains a nuclear export signal sequence that enables GK to return to the cytoplasm after metabolic cues lead to its dissociation from GKRP in the nucleus (Shiota et al., 1999). These studies have led us to suggest the existence of a novel nuclear translocation cycle for GK. However, it remains unclear how the binding of GK to GKRP actually stimulates movement of the dimerized complex into the nucleus.

\section{GK Gene Mutations in Humans}

In humans, mutations in the GK gene can cause two distinct diseases: maturity onset diabetes of the young, type 2 (MODY-2) and persistent hyperinsulinemic hypoglycemia of infancy (PHHI). Most mutations in the GK gene - in fact, over 100 different ones - have been identified that cause hyperglycemia in people (Froguel et al., 1992; Vionnet et al., 1992; Velho et al., 1997). The identification of GK as a diabetes-susceptibility gene has provided a major impulse for the reassessment of the physiological role of GK as a glucose sensor and the understanding of the pathophysiogical importance of this key enzyme in glucose ho- 
meostasis. At a biochemical level, missense mutations of GK impair either or both the $\mathrm{V}_{\max }$ and $\mathrm{K}_{\mathrm{cat}} \mathrm{S}_{0.5}$ of the enzyme, although some also appear to shorten the half-life of the protein (Pilkis et al., 1994; Liang et al., 1995; Guazzini et al., 1998; Miller et al., 1999). In addition to the effects of mutations on the $\mathrm{K}_{\mathrm{cat}} \mathrm{S}_{0.5}$ and $V_{\max }$, a decrease in the ATP-binding affinity or stability of the mutated enzyme may contribute to a reduction of GK activity in some individuals. Other mutations impair GK gene expression by affecting splice site utilization or by leading to premature termination of protein translation. In all cases, whether by activity or gene expression, the net effect is a reduction in the amount of GK activity within cells.

Congenital hyperinsulinism is a clinically and genetically heterogeneous disease. While most cases that have been described are caused by mutations in the sulfonylurea receptor-type 1 , a component of the ATP-sensitive potassium channel in $\beta$ cells (Thomas et al., 1995), mutations in other genes have been identified in patients with this clinical syndrome. Indeed, in one instance, the disease is due to a mutation in GK (V455M) that has the unusual effect of increasing the catalytic activity of the enzyme (Glaser et al., 1998). Given this important observation, as well as the fortuitous finding during experimental analysis of a second mutation capable of enhancing the activity of GK (Davis et al., 1999), it is possible that additional mutations that cause hypoglycemia will be identified.

\section{Rationale for Studies in Mice}

Given that GK is expressed in the liver, pancreatic islet, brain, and gut tissues that play central and interacting roles in controlling the blood glucose concentration - and that the regulation of GK activity is complex, a full understanding of how mutations in this enzyme cause either hyperglycemia or hypoglycemia can be achieved only in animal model systems. Indeed, given the complex nature of the regulation of both the islet and hepatic GK isoforms, as well as the fact that they arise from the same gene, it is unlikely that we will ever accurately predict the in vivo ramifications of altered GK gene expression by simply extrapolating from in vitro experimental model systems. Due to these various issues, controversy has persisted about the relative contributions of the liver and the islet in perturbations of glucose homeostasis observed in humans with GK gene mutations.

Part of the problem in determining the role of GK in glucose homeostasis is that both the liver and islet, key sites of GK gene expression, participate in a glucose-insulin feedback loop (Meglasson and Matschinsky, 1986; Magnuson, 1990). For instance, the secretion of both insulin and glucagon occurs in response to changes in the plasma glucose concentration, which is, in turn, affected by the metabolic status of the liver. Similarly, in the islet, glucose modulates islet GK 
content, probably by directly affecting the half-life of the enzyme (Liang et al., 1990,1992). The translocation of GK in hepatocytes between the cytoplasm and the nucleus is another good example of the complexity of the mechanisms involved. Indeed, the blood glucose concentration is a physiological endpoint that is determined by a myriad of different biochemical and physiological interactions. Thus, we thought it was necessary to generate several animal models with specific differences in GK gene expression and to carefully determine their phenotypes, in order to obtain unambiguous experimental information about tissue-specific roles of GK in regulating the blood glucose concentration.

\section{Effects of Overexpressing GK in Mice}

The effects of increased GK gene expression on blood glucose homeostasis were first examined by generating transgenic mice that contained additional copies of the entire mouse GK gene locus (Niswender et al., 1997a). These studies made use of the 83-kb fragment of mouse DNA, described earlier, that contained both the upstream and downstream promoters, all coding exons, as well as a large amount of tlanking DNA sequence (Postic et al., 1995). Indeed, the latter fact was an important consideration since, prior to these studies, a DNA fragment capable of regulated expression of GK in liver had not been demonstrated. By pronuclear DNA microinjection experiments using this DNA fragment, a line of transgenics that contained a single extra copy of the entire GK gene locus was generated. This was fortuitous, since it allowed the effects of increased GK gene copy number on glucose homeostasis to be studied.

In the GK gene locus transgenic mice, GK mRNA concentration was increased by approximately 1.5 fold in heterozygous transgenic animals and by about twofold in homozygous animals (Niswender et al., 1997a). Mice with a single extra copy of the GK gene locus had a plasma glucose concentration 25 percent lower than littermates with two normal alleles. Animals with a total of four functional copies of the GK gene had a plasma glucose concentration that was reduced even further (Figure 1). The effect of increased GK gene number on whole-body homeostasis was assessed further by performing both basal and hyperglycemic clamp studies (Niswender et al., 1997b). This involved implanting two catheters that enabled the precise determination of rates of hepatic glucose utilization and of insulin secretion under both basal and hyperglycemic conditions. During the hyperglycemic clamp study, a variable infusion of glucose was used to raise blood glucose levels to about $300 \mathrm{mg} / \mathrm{dl}$. Glucose turnover and glucose clearance rates as well as net hepatic and muscle glycogen are measured by incorporating the use of $\left[3-{ }^{3} \mathrm{H}\right]$ glucose as a metabolic tracer. The glucose infusion rate required to maintain the plasma glucose at this level provides an index of glucose tolerance. 


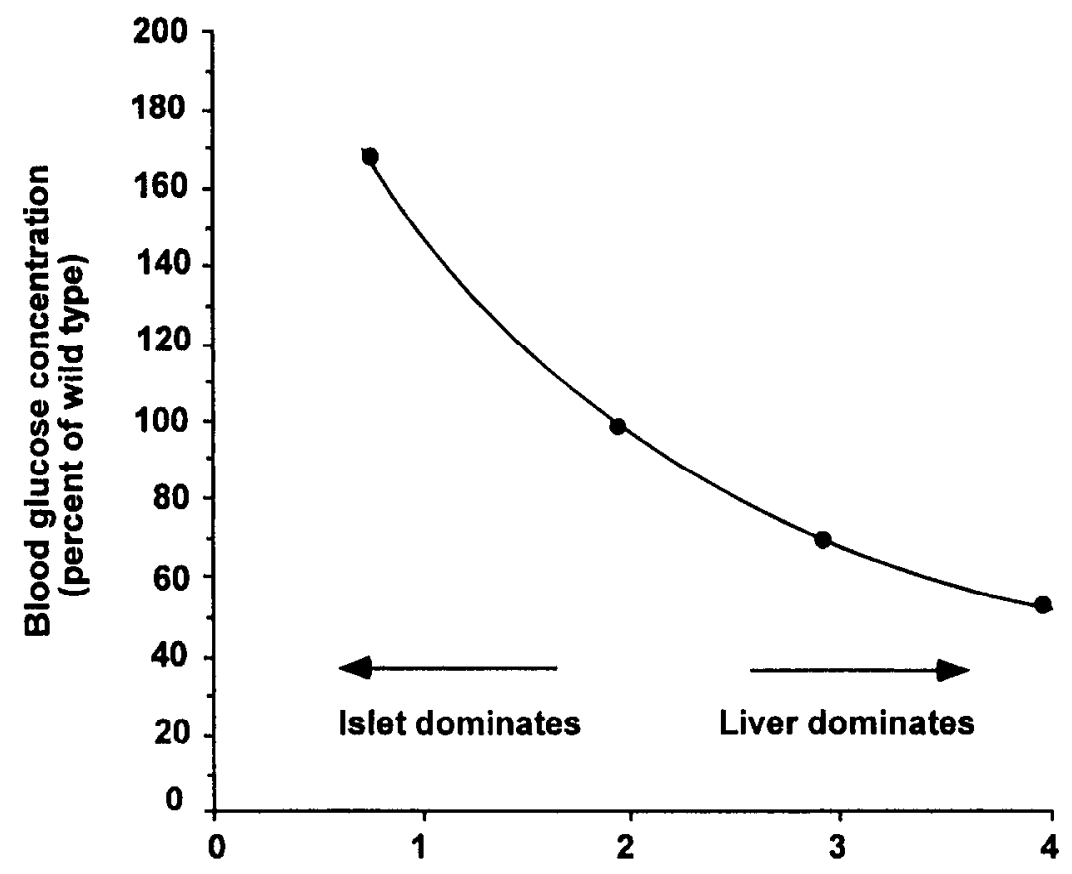

GK gene copy number

FIG. 1. Relationship between GK gene copy number and the blood glucose concentration. This figure shows the effect on the blood glucose concentration of changes in the GK gene copy number, obtained from GK-overexpressing transgenic mice and heterozygous global GK knockout mice. Mice that totally lack GK have blood glucose concentration greater than $500 \mathrm{mg} / \mathrm{dl}$ and do not survive the neonatal period, as described previously. [Adapted with permission from Postic, C., and Magnuson, M.A. Front. Diabetes 15, 293-298, 2000. Copyright 2000 by Karger, Basel.]

Increased GK gene expression from the presence of the GK gene locus transgene resulted in a 21 percent increase in glucose clearance rate under basal conditions, in the absence of any difference in basal insulin concentrations (Niswender, et al., 1997b). This result clearly demonstrated a role for GK in determining the basal rate of glucose clearance. Under hyperglycemic conditions, GK transgenic mice had glucose turnover and clearance rates similar to controls but secreted about 50 percent less insulin (Table I). Interestingly, despite diminished insulin secretion, hepatic glycogen content was markedly increased after the 2-hour glucose infusion (Niswender, et al., 1997b).

Transgenic mice that overexpress GK in the liver have been generated by other groups (Ferre et al., 1996; Hariharan et al., 1997). The results of these studies, which are similar to ours, have confirmed a direct role for hepatic GK in 
TABLE I

Summary of Metabolic Parameters from Basal and Hyperglycemic Clamp Experiments

\begin{tabular}{|c|c|c|c|c|c|c|c|c|}
\hline \multirow[b]{2}{*}{ Mouse Model } & \multicolumn{4}{|c|}{ Basal } & \multicolumn{4}{|c|}{ Hyperglycemic Clamp } \\
\hline & $g k^{3}$ & $g k^{\mathrm{del} / \mathrm{w}}$ & $\begin{array}{l}g k^{\mathrm{lox} / \mathrm{w}}+ \\
\text { Rip-Cre }\end{array}$ & $\begin{array}{l}\boldsymbol{g h}^{\text {lox/ox }}+ \\
\text { Alb-Cre }\end{array}$ & $g k^{3}$ & $g k^{\mathrm{del} / \mathrm{w}}$ & $\begin{array}{l}\text { gk } k^{10 x / \mathrm{w}}+ \\
\text { Rip-Cre }\end{array}$ & $\begin{array}{l}g k^{l o x} / 0 x+ \\
\text { Alb-Cre }\end{array}$ \\
\hline Blood glucose & $-12 \%$ & $+38 \%$ & $+23 \% *$ & $+40 \% *$ & $-40 \% *$ & \multicolumn{3}{|c|}{ Raised to $\sim 300 \mathrm{mg} / \mathrm{dl}$} \\
\hline Plasma insulin & nd & nd & nd & nd & $-40 \% *$ & $-70 \% * *$ & $-70 \% * *$ & $-70 \% * *$ \\
\hline Glucose turnover & nd & $-50 \% *$ & nd & nd & nd & $-67 \% *$ & $-56 \% *$ & $-60 \% *$ \\
\hline Glycogen synthesis & - & - & - & - & $+360 \% * *$ & $-90 \% * *$ & $-55 \% *$ & $-88 \%$ ** \\
\hline
\end{tabular}

The following mouse models were used: $\boldsymbol{g} \boldsymbol{k}^{3}$ : transgenic mice over expressing the entire GK gene locus (three functional genes in all tissues); $\boldsymbol{g}^{\text {del/w: }}$ heterozygoL GK knockuul mice (une functional gene in all tissues); $g k^{\text {tox } / w}+$ Rip-cre: heterozygous $\beta$-cell-specific GK knockout mice (a single functional gene in the $\beta$ cell, tw elsewhere); $g^{\text {loxhox }}+\boldsymbol{A l b}$-cre: liver-specific GK knockout mice (no hepatic GK, two functional genes elsewhere). For the hyperglycemic clamp studies, blood glucos concentrations were raised to $-300 \mathrm{mg} / \mathrm{dl}$. Each group of mice was comparcd to its appropriate control and differences between parameters are expressed as percer of controls. Only significant values are indicated in the table. nd: not statistically different. ${ }^{*} p<0.05 ; * \mathrm{p}<0.001$. 
maintaining basal plasma glucose concentration. Together, they clearly demonstrate that increased hepatic GK, by itself, is able to increase the rate of glucose clearance by the liver without increasing insulin secretion. Additionally, these studies show the pivotal role that hepatic GK plays in controlling glycogen synthesis in liver (Table I). Since we used a transgene containing promoters for the islet and hepatic isoforms of GK, it is interesting that islet GK expression was not increased, as might have been expected. Instead, these animals had a diminished amount of GK in islets, probably due to development of mild hypoglycemia. This hypoglycemia probably led to a diminished amount or stability of $\beta$-cell GK (Niswender et al., 1997a). In addition, elegant studies that have made use of recombinant adenoviruses to overexpress GK in hepatocytes (Agius et al., 1996; O'Doherty et al., 1996), as well as in the liver of rats (O'Doherty et al., 1999), confirm a direct role for hepatic GK in determining hepatic glucose uptake and, consequently, in maintaining basal plasma glucose concentration. Therefore, the role of liver in determining the blood glucose concentration appears to dominate in the situation of increased GK gene expression, as occurs in the gene locus transgenic mice (Niswender et al., 1997a). These results suggest that, normally, there is a fine balance between the function of the liver and the islet in the usual situation of two functional GK gene copies. Any perturbation in GK gene expression would cause a change in the blood glucose concentration by shifting the glucose setpoint (Niswender et al., 1997b).

Overexpression of GK, besides reducing the blood glucose concentration, appears to prevent the development of type 2 diabetes. Male GK locus transgenic mice that were fed a high-fat diet were protected against the development of hyperinsulinemia and hyperglycemia, even though these animals were as obese as their nontransgenic littermates (Shiota $e t$ al., in press). This suggests that if GK activity could somehow be enhanced, it might be an effective strategy of treating diabetes.

\section{Conventional GK Gene Knockout Mice}

Information complementary to the GK gain-of-function studies has been obtained by three groups who used gene-targeting studies to totally eliminate GK gene expression or to knock out expression only of the islet GK isoform (Bali et al., 1995; Grupe et al., 1995; Terauchi et al., 1995). In all cases, heterozygous GK knockout mice were hyperglycemic, thereby indicating that studies in the mouse provide a relevant model for MODY-2. Furthermore, all of the heterozygous GK null mouse models showed defective insulin secretion in response to glucose, indicating that the haploinsufficiency of GK impairs insulin secretion. This finding is consistent with the proposed role of GK as glucose sensor in the cell (Bali et al., 1995; Grupe et al., 1995; Terauchi et al., 1995). However, the 
fact that the global lack of GK is lethal either at midgestation (Bali, et al., 1995) or a few days after birth (Grupe et al., 1995) has prevented a detailed physiological analysis in these animal models. Additionally, none of these studies allowed the function of GK in the liver to be directly examined.

\section{Tissue-specific GK Gene Knockouts Using the Cre-loxP Approach}

To overcome the limitations of conventional gene-targeting approaches, we made use of a conditional targeting strategy in the site-specific DNA recombinase Cre to investigate the cell-specific roles of GK in glucose homeostasis. The Cre/lox $P$ recombinase system has been found to function efficiently both in vitro and in vivo (Sauer and Henderson, 1988; Sauer, 1993). Cre catalyzes recombination between two 34-bp recognition elements, termed loxP sites, thereby causing excision of intervening sequences. A virtually 100 percent excision efficiency can be achieved by transient expression of the Cre recombinase in embryonic stem (ES) cells or by pronuclear injections in zygotes (Araki et al., 1995). Transgenic mouse lines that express Cre under tissue-specific promoters can be crossed with mice harboring loxP sites to achieve gene excision in specific cell types. However, the difficulty of the technique resides in the need to obtain reliable Cre transgenic lines in which this recombinase is expressed in a cell-specific manner. While this method provides many advantages over a conventional gene knockout, the strategy is more complex because two components are necessary. First, a conditional gene locus is made by inserting two or more lox $P$ sites in nonessential portions of the gene, usually introns, by gene targeting in ES cells. This results in a gene locus that remains functional until exposed to Cre, which then causes excision of intervening sequences. For our studies, lox $P$ sites were inserted into the GK gene between exons 8 and 9 and downstream of exon 10, generating the loxed GK allele $\left(g k^{\text {lox }}\right)$ shown in Figure 2. The second essential component is a transgenic mouse that expresses Cre under the control of one or another different, cell type-specific promoters. For our studies, we generated transgenic mice that expresses $C r e$ under the control of either the insulin or the albumin promoters. These mice expressed this site-specific recombinase in pancreatic $\beta$ cells and hepatocytes, respectively (Figure 3 ). By crossing the $g k^{\text {tox }}$ allele into mice bearing one or another of the Cre transgenes, we were able to specifically eliminate GK in either $\beta$ cells or in the liver. In addition, by microinjecting a Cre expression plasmid into single-cell mouse embryos, we were able to generate a null allele $\left(g k^{\mathrm{del}}\right)$, thereby generating mice that confirm the effects of a global GK gene knockout (Postic et al., 1999). 


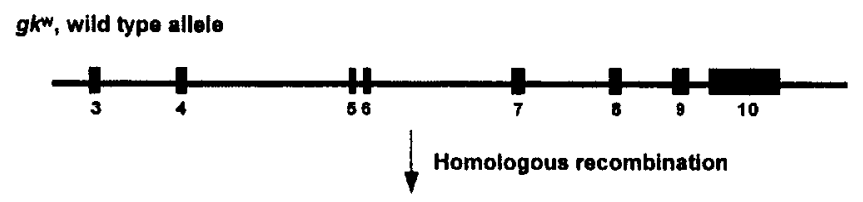

gklox+neo

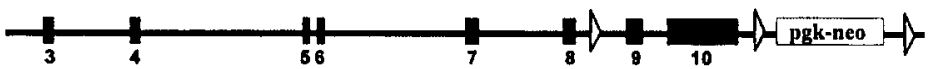

Cre expression in cells or embryos

gklox, conditional allele

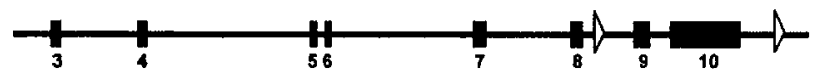

Cell-specific recombination using Cre transgenic mice

gkdel, deleted allele (null)

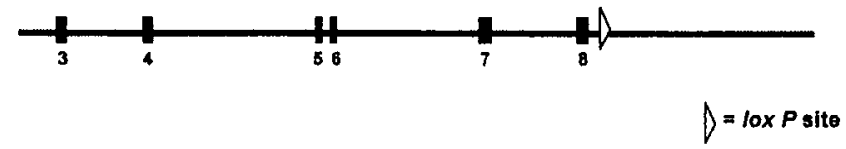

FIG. 2. Generation of mice with conditional $g k$ gene alleles. Exons are indicated as solid rectangles. A partial map of the wild-type allele $\left(g k^{\mathrm{w}}\right)$ is shown. The conditional allele was obtained by homologous recombination in ES cells and partial Cre recombination $\left(g k^{\text {lox }}\right)$. The deleted allele ( $g k^{\text {del }) ~ l a c k s ~ e x o n s ~} 9$ and 10 and was obtained by microinjection of a Cre expression plasmid into single-cell mouse embryos or by cell-specific expression of Cre in transgenic mice.

\section{A. GLOBAL GK NULL MICE}

To determine the effect of a total deletion of GK, we converted the $g k^{\text {lox+neo }}$ allele into a deleted allele $\left(g k^{\mathrm{del}}\right)$ by microinjecting different concentrations of a CMV-Cre expression plasmid into single-cell $g k^{\mathrm{lox}+\text { neo/w }}$ mouse embryos (Araki $e t$ $a l ., 1995)$. At concentrations of $0.1 \mathrm{ng} / \mu \mathrm{l}$ or greater, Cre efficiently excised both loxP-flanked DNA fragments, thereby creating several mice that were heterozygous for the $g k^{\mathrm{del}}$ allele (e.g., $g k^{\mathrm{del} / \mathrm{w}}$ ). Intercrossing of $g k^{\mathrm{del} / \mathrm{w}}$ resulted in mice that were homozygous null for GK $\left(g k^{\mathrm{del} / \mathrm{del}}\right)$. These mice appeared normal at birth but died within 4 days of profound hyperglycemia. The metabolic alterations observed in $g k^{\text {del/del }}$ pups, particularly hepatic steatosis and decreased glycogen content, were consistent with insufficient insulin secretion due the inability of $\beta$ cells in the GK null mice to respond to an elevated plasma glucose concentration. Indeed, mice that have induced mutations of both insulin genes have nearly an identical phenotype (Duvillie et al., 1997). This phenotype closely resembled that of Grupe 


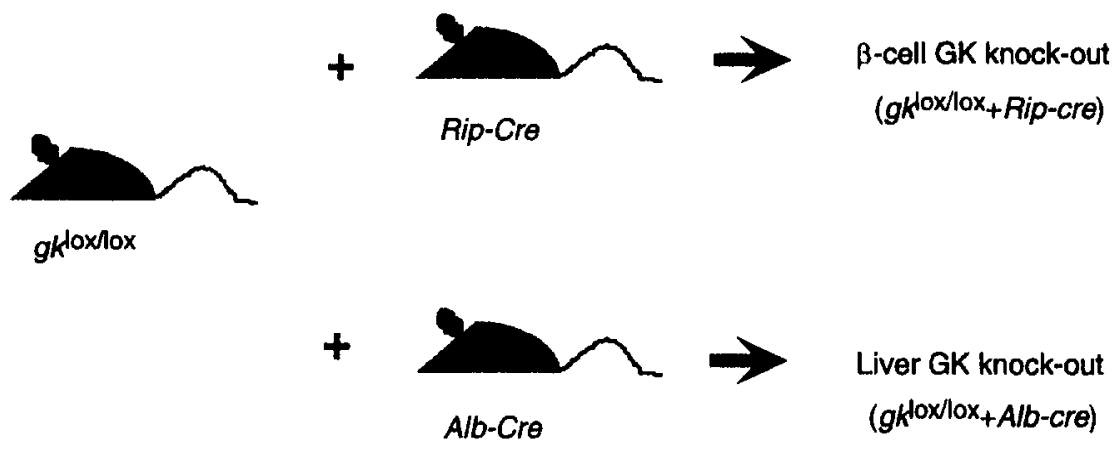

FIG. 3. Strategy for $\beta$-cell- and liver-specific deletion of the $g k^{\text {tox }}$ allele in mice. Two lines of Cre transgenic mice were created. Rip-cre transgenic mice express $C r e$ in the pancreatic $\beta$ cells under the control of the rat insulin promoter. Alb-cre transgenic mice express Cre in liver under the control of the promoter/enhancer albumin gene. Intercrossing Cre transgenic mice with $g k^{\text {lox } \lambda_{0 x}}$ mice produces both $\beta$-cell and liver-specific GK gene knockout animals.

et al. (1995) but was substantially different from mice generated by Bali et al. (1995), which died in utero at embryonic day 9.5. We think this difference is due to the random insertion of a second copy of the targeting vector in the genome of the mice made by Bali et al. (1995), as indicated by the presence of an unexpected band after hybridization of DNA from these mice with a probe containing sequences from the neomycin resistance cassette (Niswender et al., 1997a). This may have led to the inadvertent knockout of a second gene whose function is necessary during early embryogenesis.

\section{B. $\beta$-CELL-SPECIFIC KNOCKOUT OF GK}

To unambiguously determine the role of GK in pancreatic $\beta$ cells, mice with the conditional GK allele $\left(g k^{\mathrm{lox}}\right)$ were interbred with animals that express Cre under the control of a 668-bp fragment of the rat insulin 2 promoter (Rip-Cre) (Figure 3). The Rip-Cre transgene contained the entire human growth hormone gene placed downstream of the Cre coding sequences that had been modified to contain a nuclear localization signal sequence and an optimized translation start site. All of these features were included to ensure high-fidelity expression of this recombinase. Moreover, since Cre-mediated conditional gene inactivation requires precise knowledge of sites of recombination, we also used ROSA26 LacZ reporter mice (Soriano, 1999) to determine sites of Rip-Cre expression, both during mouse development and in the adult animal (Gannon et al., 2000). Rip-Cre mediated recombination was first detected in early developmental (i.e., 11.5 days postcoitum) pancreatic endocrine cells (Gannon et al., 2000). In adult mice, 
recombination was first detected within pancreatic $\beta$ cells and in the ventral cerebral cortex and some neurons (Gannon et al., 2000). Beta-cell-specific GK knockout mice (e.g., $g k^{\text {lox/lox }+R i p-C r e)}$ are phenotypically similar to animals with a global GK knockout, showing signs of steatosis and a depletion of hepatic glycogen content due to approximately a 70 percent decrease in plasma insulin concentrations. Furthermore, the $g k^{\mathrm{lox} / \mathrm{ox}}+R i p-C r e$ die within a few days of birth as a result of severe diabetes. Both basal and hyperglycemic clamp studies of the heterozygous $\beta$-cell-specific GK knockout mice $\left(g k^{\text {lox/w }}+R i p-C r e\right)$ showed that they had fasting hyperglycemia $(+25 \%)$ without measurable difference in basal insulin levels (Table I). During the hyperglycemic clamp, glucose turnover rates and insulin secretion were reduced by about $70 \%$. Moreover, as a consequence of diminished insulin secretion, net glycogen synthesis in liver was reduced by nearly 50 percent.

\section{LIVER-SPECIFIC KNOCKOUT OF GK}

To determine the role of hepatic GK in glucose homeostasis, we next generated liver-specific GK knockout mice (e.g., $g k^{\mathrm{lox} / \mathrm{ox}}+A l b-C r e$ ) by interbreeding albumin-Cre transgenic mice with animals bearing the loxed GK allele (Figure 3). Cre expression in hepatocytes was obtained using a $2.35-\mathrm{kb}$ rat albumin enhancer/promoter fragment (Pinkcrt et al., 1987). Otherwise, the transgenic design was similar to that used for expression of $\mathrm{Cre}$ in the $\beta$ cell. To examine the efficiency of recombination as a function of age, we performed Southern blot analysis using liver genomic DNA from $g k^{\mathrm{lox} / \mathrm{lox}}+A l b$-Cre mice isolated at ages ranging from 1 day to 12 weeks. The timing of recombination in liver of $g k^{\mathrm{lox} / \mathrm{lox}}+A l b$-Cre mice, while age dependent, appeared to be complete by 6 weeks of age (Postic and Magnuson, 2000a). Moreover, when the Alb-Cre transgene was crossed with the ROSA26A Cre-inducible reporter mice, more than 99 percent of hepatocytes showed positive $\beta$-galactosidase staining at 12 days of age. The lack of complete recombination at birth in $g k^{\text {lox/lox }}+A l b$-Cre mice and progressive recombination thereafter is likely due to expression of Cre below the threshold level necessary to cause rapid recombination (Postic and Magnuson, 2000a). Nonetheless, by 6 to 8 weeks of age, recombination in liver was complete and there was no evidence for Cre-mediated deletion of the loxed GK gene locus in other tissues.

The complete loss of hepatic GK was not lethal and had only a relatively small effect on the plasma glucose concentration (Postic et al., 1999). Indeed, mice totally lacking hepatic GK had fed blood glucose values that were only about 10 percent higher that their $g k^{\text {lox/lox }}$ littermates. Again, to explore the consequences of the total loss of hepatic GK on both insulin secretion and hepatic fluxes, basal and hyperglycemic clamp studies were performed (Table I). After an 8-hour fast, no differences were detected in either plasma insulin concentration or glucose 
turnover rate, even though the blood glucose concentrations were higher $(+40$ percent) than the controls. During the hyperglycemic clamp phase of the study, glucose turnover rate was markedly reduced in the liver-specific GK knockout mice (Table I). Surprisingly, the liver-specific GK knockout mice secreted 70 percent less insulin in response to the glucose stimulus, compared to controls (Table I; Figure 4A), a finding that will be discussed in more detail. Net glycogen synthesis was reduced by approximately 90 percent in liver (Figure 4B). In addition, several glucose-responsive genes, including L-pyruvate kinase and phosphoenolpyruvate kinase, were found to be inappropriately regulated (Postic $e t a l$., unpublished data). Together, these results clearly indicate that hepatic GK plays an important role in glucose homeostasis, largely by a direct effect on hepatic glucose utilization but possibly also by an indirect effect on insulin secretion.

\section{Importance of GK in Glucose Homeostasis and Glucose Sensing}

\section{A. ROLE OF $\beta$-CELL GK}

An extensive body of evidence indicates that GK plays a critical role in the control of insulin secretion in the $\beta$ cells. Insulin secretion depends upon glucose metabolism and GK exerts nearly total control on the rate of glycolysis in these cells (Meglasson and Matschinsky, 1986; Matschinsky et al., 1993). Indeed, the control strength of GK for metabolic flux is close to unity (Sweet et al., 1996), implying that even small changes in total $\beta$-cell GK activity have an impact on the rate of glucose metabolism and, hence, the rate of glucose-induced insulin release.

In our mouse models, as well as those of other investigators, the reduced level of GK activity in $\beta$ cells appears to be responsible for much of the hyperglycemia that developes as a result of diminished GK gene expression, as occurs in MODY2 (Bali et al., 1995; Grupe et al., 1995; Terauchi et al., 1995, Postic et al., 1999). Interestingly, despite the close similarities between mice and humans in the mechanisms used to maintain glucose homeostasis, the loss of one functional GK allele in mice may result in a greater degree of hyperglycemia than is observed in humans. In several subjects with GK gene mutations that were studied by Sturis et al. (1994), insulin secretion was found to be reduced compared to controls but less than predicted from the calculated decrease in GK flux, suggesting the existence of compensatory changes. These changes include a potential glucoseinduced overexpression of the normal allele or a decrease in the inhibitory effect of the regulatory protein (Sturis et al., 1994). Using islets isolated from a linc of heterozygous GK knockout mice, Sreenan and colleagues have shown that these islets may be protected against the toxic effect of high glucose through enhanced expression of GK protein and activity, resulting from the remaining normal allele 
A

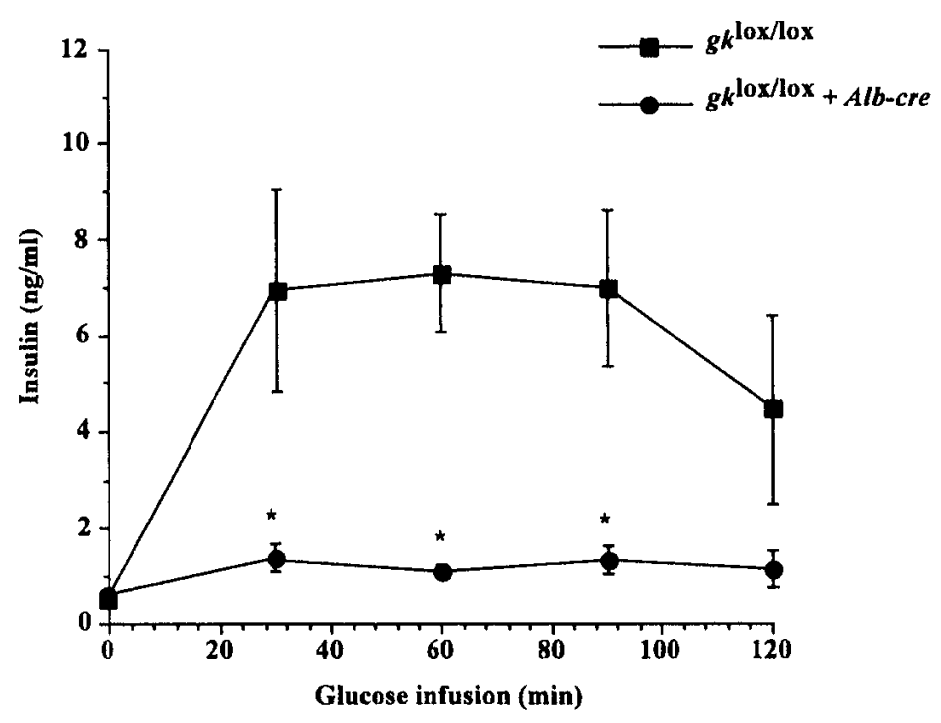

B

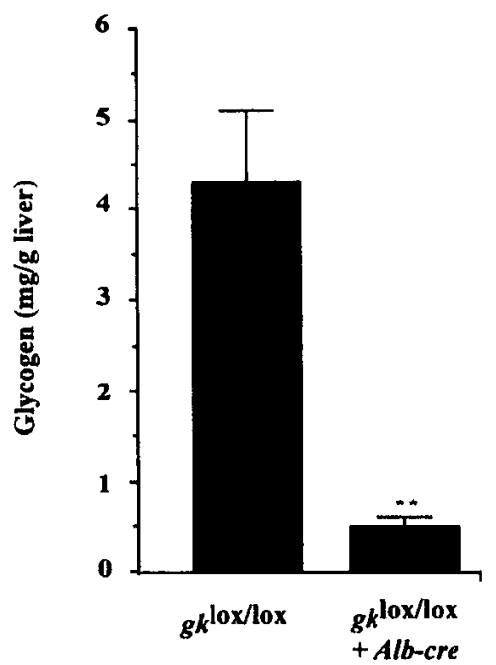

FIG. 4. Impaired insulin secretion and reduced glycogen content in liver of $g k^{\text {lox/lox }}+A l b-c r e$ mice. (A) $g k^{\mathrm{lox} / 0 \mathrm{x}}+A l b$-cre mice secreted 70 percent less insulin in response to the glucose stimulus, compared to controls. (B) Net hepatic glycogen synthesis, measured at the end of the 2-hour hyperglycemic clamp, was reduced by about 90 percent in liver of $g k^{\text {lox } \lambda \text { ox }}+A l b$-cre mice, compared to their controls. 
(Sreenan et al., 1998). These studies suggest that there is compensation by the functional GK allele in the heterozygous GK null mice to hyperglycemia, perhaps explaining why MODY-2 in humans is characterized by mild hyperglycemia that generally does not worsen over time.

While physiological studies of the $\beta$-cell-specific GK knockout mice have provided compelling data indicating a role for GK in determining insulin secretion, additional evidence for GK functioning as the $\beta$-cell glucose sensor was obtained by Piston et al. (1999). In this study, islets from $g k^{\text {lox/lox }}$ mice were isolated and treated with a recombinant adenovirus that expresses Cre (Anton and Graham, 1995). This caused the elimination of GK expression from some $\beta$ cells, while retaining it in others. Two-photon excitation microscopy of these islets was then used to show that individual $\beta$ cells that lack GK do not have a normal rise in NADP(H) autofluorescence, in contrast to cells that contain GK (Piston et al., 1999). Interestingly, while confirming the key role of GK in the metabolism of glucose by $\beta$ cells, these studies have suggested that one or another of the three known lower $K_{\mathrm{m}}$ hexokinases may play a small role in determining insulin secretion but probably only at low blood glucose concentrations. GK clearly plays the dominant role in determining glucose-induced insulin secretion (Piston et al., 1999). In any case, these studies illustrate the experimental flexibility of Cre-loxP technology and suggest that recombinant Cre-expressing adenoviruses will be generally useful for deleting other loxed alleles in isolated islets.

\section{B. ROLE OF HEPATIC GK}

While it has been widely assumed for years that GK is necessary for hepatic glucose metabolism, the complete loss of hepatic GK is not lethal. In fact, it has only a relatively small effect on the plasma glucose concentration. In addition, both glycogen concentrations and a number of other plasma and hepatic metabolites in these animals are normal at the basal state. Surprisingly, GLUT-2 knockout mice show a more-severe hepatic phenotype, including dysregulation of both glycogen metabolism and abnormal expression of some glucose-responsive genes (Burcelin et al., 2000). The fact that basal glucose turnover rates in mice totally lacking GK are similar to control animals suggests that a near-normal flux can be maintained at the basal state through one or another of the low $K_{\mathrm{m}}$ hexokinases. Indeed, the effect of a deficiency of hepatic GK becomes apparent only under hyperglycemic conditions, when an impairment in glucose turnover, glucose clearance, hepatic glycogen synthesis, and insulin secretion become apparent (Table I; Figure 4). During hyperglycemia, the phosphorylating capacities of all of the low $K_{\mathrm{m}}$ hexokinases likely become saturated, thereby leading to functional deficits that have been observed. Whether increased activity from one or another of low $K_{\mathrm{m}}$ hexokinase compensates for the lack of hepatic GK in $g k^{\text {lox/lox }}+A l b-C r e$ mice remains to be determined. It also appears that the lack of hepatic GK impairs 
the ability of certain hepatic genes to respond to changes in the glucose concentration, which is consistent with hepatic GK functioning as a glucose sensor in the liver, much as it does in the $\beta$ cell.

The finding of a blunted insulin secretory response to hyperglycemia was unexpected and unexplained. It seems unlikely that this is due to glucose toxicity, since these mice have only a small elevation in basal plasma glucose concentrations. Moreover, we have found no evidence for recombination in $\beta$ cells of liver-specific GK knockout mice (C. Postic, data not shown). It is possible that hepatic GK is somehow necessary for the function of a neural regulatory loop or for the secretion of a factor whose function is to modulate insulin secretion. However, it could also simply reflect a lower insulin clearance rate. Thus, this intriguing observation merits further study. In any case, these findings indicate that alteration in GK expression in the liver, in addition to the $\beta$ cell, probably contributes to the pathogenesis of MODY-2. Thus, while the total loss of hepatic GK has less of an impact on the animal than that of $\beta$-cell GK, these studies provide clear evidence that hepatic GK plays an important role in determining hepatic glucose utilization during hyperglycemia. Hepatic GK also enables the induction of other key hepatic genes in response to glucose.

The finding that deficiencies of both hepatic and $\beta$-cell GK cause hyperglycemia in mice is consistent with findings by other investigators who have studied individuals with MODY-2. Indeed, these studies have shown that GK gene mutations are associated with abnormal regulation of hepatic glucose output and glycogen synthesis (Velho et al., 1996; Tappy et al., 1997). Furthermore, the high control coefficient exerted by GK on glucose metabolism (Agius et al., 1996) is consistent with the dominant inheritance pattern of MODY-2. Abnormal suppression of hepatic glucose production has been demonstrated in heterozygous GK knockout mice (Rossetti et al., 1997). Indeed, the inability of hyperglycemia to inhibit hepatic glucose production is fully consistent with GK functioning as a hepatic glucose sensor for regulating gene expression by glucose. Taken together, both the gain-of-function and loss-of-function studies that have been performed indicate that hepatic GK is a major determinant of glucose homeostasis.

\section{Toward Further Understanding of Type 2 Diabetes Mellitus Using Cre-loxP}

Type 2 diabetes is now understood to be a complex metabolic disorder caused by two main physiological defects, resistance to the action of insulin combined with a deficiency in insulin secretion (De Fronzo, 1997). Because the molecular defects that cause type 2 diabetes are largely unknown, a large number of animal studies have been undertaken by different investigators to determine how different gene defects contribute or cause a diabetic phenotype. Further application of the 
Cre/loxP strategy is likely to yield novel insights into the role of specific tissues in the development of insulin resistance and type 2 diabetes. While our studies have been focused on understanding how a haploinsufficiency of GK is able to cause hyperglycemia, there are other forms of MODY caused by mutations in genes encoding several different transcription factors. Specifically, mutations in HNF-4 $\alpha$ (Yamagata et al., 1996a), HNF-1 $\alpha$ (Yamagata et al., 1996b), PDX-1 (Stoffers et al., 1997a,1997b), and HNF-1 $\beta$ (Horikawa et al., 1997) cause MODY$1,-3,-4$, and -5 , respectively. These transcription factors are expressed in pancreatic $\beta$ cells. The mutations are believed to cause insulin deficiency by impairing $\beta$-cell function. However, because HNFs are also expressed in hepatocytes, these mutations may cause abnormalities in hepatic metabolism. While the generation of HNF- $1 \alpha$ null mice has shed some light on the molecular basis of MODY-1 (Lee et al., 1998; Pontoglio et al., 1998), analysis of mice with a tissue-specific defect in HNF-1 $\alpha$ expression would clearly resolve the contribution of the liver and pancreatic islets in the pathogenesis of the disease.

Recently, Cre/lox $P$ methodology has been used to begin to sort out the physiological effects of insulin resistance in various tissues. Although mice with a global insulin receptor defect die of uncontrolled diabetes (Accili et al., 1996; Joshi et al., 1996), mice with tissue-specific knockouts of insulin receptor are viable (Bruning et al., 1998; Kulkarni et al., 1999; Michael et al., 2000). Analysis of mice with a liver-specific insulin receptor knockout (LIRKO) has revealed the critical role that hepatic insulin signaling plays in the regulation of glucose homcostasis and maintenance of normal hepatic function (Michael et al., 2000). Indeed, LIRKO mice exhibit dramatic insulin resistance, severe glucose intolerance, and a failure of insulin to suppress hepatic glucose production and to regulate hepatic gene expression (Michael et al., 2000). In the liver of LIRKO mice, genes encoding a variety of different hepatic enzymes, known to be regulated both by insulin and glucose, are either induced or repressed (Michael et al., 2000). Whether this effect is caused by the virtual absence of hepatic GK in liver of LIRKO mice or by a direct loss of hepatic insulin signaling remains to be determined. Given that mice with a muscle-specific insulin receptor knockout (MIRKO) have normal fasting glucose levels and normal glucose tolerance (Bruning et al., 1998), the liver may play a more-important role in the control of glucose homeostasis than has been previously thought. Moreover, studies of mice with a selective defect in pancreatic $\beta$-cell insulin receptor (BIRKO) suggest that insulin resistance in $\beta$ cells may contribute to the inability of these cells to sustain sufficient insulin secretion (Kulkarni et al., 1999). How this occurs is not known; however, because there is a selective loss of glucose-stimulated insulin secretion, it is possible that expression of islet GK is impaired in the BIRKO mice. Whether or not this is the case, further studies of how insulin signaling affects $\beta$-cell 
function is clearly needed and may lead to dramatic changes in our understanding of how this cell contributes to the pathogenesis of type 2 diabetes.

\section{Concluding Comments}

In conclusion, our studies have illustrated how various mousc models, some of which used Cre-loxP methodologies, have been valuable for determining the pathophysiological basis of MODY-2. Since type 2 diabetes is even a more-complex physiological disorder, we expect that various site-specific recombinases, particularly Cre, are likely to see additional use in determining the cell-specific functions of genes in intact animals. Indeed, by enabling specific genes to be activated or deleted in virtually any tissue, Cre/loxP is certain to be a very important tool in mouse functional genomics, as suggested by various recent reviews (Nagy, 2000; Le and Sauer, 2000; Hardouin and Nagy, 2000).

\section{ACKNOWLEDGMENTS}

These studies were supported by grants from the National Institutes of Health (NIH) (DK42612 and DK 42502). We thank K.D. Niswender, Y. Chen, J.M. Moates, K.D. Shelton, J. Lindner, S. Knobel, D. Piston, A.D. Cherrington, M. Gannon, and C. Wright for their participation in the primary studies that are summarized here.

\section{REFERENCES}

Accili, D., Drago, J., lee, E., Johnson, M., Cool, M., Salvatore, P., Asico, L., Jose, P., Taylor, S., and Westphal, H. (1996). Nature Genet. 12, 106-109.

Agius, L., Peak, M., Newgard, C.B., Gomez-Foix, A.M., and Guinovart, J.J. (1996), J. Biol. Chem. 271, 30479-30486.

Aiston, S., Trinh, K.Y., Lange, A.J., Newgard, C.B., and Agius, L. (1999). J. Biol. Chem. 274, 24559-24566.

Anton, M., and Graham, F.L. (1995). J. Virol. 69, 4600-4606.

Araki, K., Araki, M., Miyazaki, J., and Vassalli, P. (1995). Proc. Natl. Acad. Sci. U.S.A. 92, 160-164.

Bali, D., Svetlanov, A., Lee, H.-W., Fusco-DeMane, D., Leiser, M., Li, B., Barzilai, N., Surana, M., Hou, H., Fleisher, N., DePinho, R., Rossetti, L., and Efrat, S. (1995). J. Biol. Chem. 270, 21464-21467.

Bosco, D., Meda, P., and lynedjian, P.B. (2000). Biochem. J. 15, 215-222.

Brown, M.S., and Golstein, J.L. (1997). Cell 89, 331-340.

Bruning, J.C., Michael, M., Winney, J., Hayashi, T., Horsch, D., Accili, D., Goodyear, L., and Kahn, C.R. (1998). Mol. Cell. 2, 559-569.

Burcelin, R., Munoz, M.C., Guillam, M.-T., and Thorens, B. (2000). J. Biol. Chem. 275, 10930-10936.

Cabrera-Valladares, G., German, M.S., Matschinsky, F.M., Wang, J., and Fernandez-Meja, C. (1999). Endocrinology 140, 3091-3096.

Davis, E.A., Cuesta-Munoz, A., Raoul, M., Buettger, C., Sweet, I., Moates, M., Magnuson, M.A., and Matschskiny, F.M. (1999). Diabetologia 42, 1175-1186.

De Fronzo, R. (1997). Diabetes Rev. 5, 177-269. 
de la Iglesia, N., Veiga-da-Cunha, M., Van Shaftingen, E., Giunovart, J.J., and Ferrer, J.C. (1999). FEBS Lett. 456, 332-338.

de la Iglesia, N., Mukhtar, M., Seone, J., Guinovart, J.J., and Agius, L. (2000). J. Biol. Chem. 275, 10597-10603.

Duvillie, B., Cordonnier, N., Deltour, L., Dandoy-Dron, F., Itier, J.-M., Monthioux, E., Jami, J., Joshi, R.L., and Bucchini, D. (1997). Proc. Natl. Acad. Sci. U.S.A. 94, 5137-5140.

Farrelly, D., Brown, K.S., Tieman, A., Ren, J., Lira, S.A., Hagan, D., Gregg, R., Mookhtiar, K.A., and Hariharan, N. (1999). Proc. Natl. Acad. Sci. U.S.A. 96, 14511-14516.

Ferre, T., Riu, E., Bosch, F., and Valera, A. (1996). FASEB J. 10, 1213-1218.

Foretz, M., Giuchard, c., Ferré, P., and Foufelle, F. (1999). Proc. Natl. Acad. Sci. U.S.A. 96, 12737 12742 .

Foufelle, F., Girard, J., and Ferre, P. (1996). Adv. Enzyme Regul. 36, 199-226.

Froguel, P., Vaxillaire, M., Sun, F., Velho, G., Zouali, H., Butel, M.O., Lesage, S., Vionnet, N., Clément, K., Fougerousse, F., Tanizawa, Y., Weissenbach, J., Beckman, S.J., Lathrop, J.M., Passa, P., Permutt, M.A., and Cohen, D. (1992). Nature 356, 162-164.

Gannon, M., Shiota, C., Postic, C., Wright, C.V.E., and Magnuson, M.A. (2000). Genesis 26, 139-141. Girard, J. (1997). Annu. Rev. Nutrit. 17, 325-352.

Glaser, B., Kesavan, P., Heyman, M., Davis, E., Cuesta, A., Busch, A., Stanley, C.A., Thornton, P.S., Permutt, M.A., Matschinsky, F.M., and Herold, K.C. (1998). N. Engl. J. Med. 338, 226-230.

Grimsby, J., Coffey, J.W., Dvorozniak, M.T. Shiota, Magnuson, M.A., and Grippo, J. (2000). J. Biol. Chem. 275, 7826-7831.

Grossbard, L, and Schimke, R.T. (1966). J. Biol. Chem. 241, 3546-3560.

Grupe, A., Hultgren, B., Ryan, S., Ma, Y.H., Bauer, M., and Stewart, T.A. (1995). Cell 83, 69-78.

Guazzini, B., Gaffi, D., Mainieri, D., Multari, G., Cordera, R., Bertolini, S., Meschi, F., and Barbetti, F. (1998). Hum. Mutat. 12, 136.

Hardouin, N., and Nagy, A. (2000). Genesis 26, 245-252.

Hariharan, N., Farrelly, D., Hagan, D., Hillyer, D., Arbeeny, C., Sabrah, T., Treloar, A., Brown, K., Kalinowski, S., and Mookhtiar, K. (1997). Diabetes 46, 11-16.

Horikawa, Y., Iwasaki, N., Hara, M., Furuta, H., Hinokio, Y., Cockburn, B.N., Lindner, T., Yamagata, K., Ogata, M., Tomonaga, O., Kuroki, H., Kasahara, T., Iwamoto, Y., and Bell, G. (1997). Nature Genet. 17, 384-385.

Hughes, S.D., Quaade, C., Milburn, J.L., Cassidy, L., and Newgard, C.B. (1991), J. Biol. Chem. 266, $4521-4530$.

Iynedjian, P.B. (1998). Biochem. J. 333, 705-712.

Iynedjian, P.B., Jotterand, D., Nouspikel, T., Asfari, M., and Pilot, P.R. (1989). J. Biol. Chem. 264, 21824-21829.

Jetton, T., Liang, Y., Petterpher, C.C., Zimmerman, E.C., Cox, G.F., Horvath, K., Matchinsky, F.M., and Magnuson, M. (1994). J. Biol. Chem. 269, 3641-3654.

Jetton, T.L., Moates, J.M., Lindner, J., Wright, C.V.E., and Magnuson, M.A. (1998). Proc. Natl. Acad. Sci. U.S.A. 95, 8654-8659.

Joshi, R., Lamothe, B., Cordonnier, N., Mesbah, K., Monthioux, E., Jami, J., and Bucchini, D. (1996). EMBO J. 15, 1542-1547.

Kulkarni, R.N., Bruning, J.C., Winnay, J.N., Postic, C., Magnuson, M.A., and Kahn, C.R. (1999). Cell 96, 329-339.

Le, Y., and Sauer, B. (2000). Methods Mol. Biol. 136, 477-485

Lee, Y.H., Sauer, B., and Gonzalez, F.J. (1998). Mol. Cell Biol. 18, 3059-3068.

Liang, Y., Najafi, H., and Matschinsky, F.M. (1990). J. Biol. Chem. 265, 16863-16866.

Liang, Y., Najafi, H., Smith, R.M., Zimmerman, E.C., Magnuson, M.A., Tal, M., and Matchinsky, F.M. (1992). Diabetes 41, 792-806. 
Liang, Y., Kesavan, P., Niswender, K., Tanizawa, Y., Permutt, M.A., Magnuson, M.A., and Matchinsky, F.M. (1995). Biochem. J. 309, 167-173.

Magnuson, M.A. (1990). Diabetes 39, 523-527.

Magnuson, M.A., Andreone, T.L., Printz, R.L., Koch, S., and Granner, D.K. (1989). Proc. Natl. Acad. Sci. U.S.A. 86, 4838-4842.

Matschinsky, F.M., Glaser, B., and Magnuson, M.A. (1998). Diabetes 47, 307-315.

Meglasson, M.D., and Matschinsky, F.M. (1983). J. Biol. Chem. 258, 6705-6708.

Meglasson, M.D., and Matschinsky, F.M. (1984). Am. J. Physiol. 246, E1-E13.

Meglasson, M.D., and Matschinsky, F.M. (1986). Diabetes Metab. Rev. 2, 163-214.

Michael, M.D., Postic, C., Previs, S.F., Kulkarni, R.N., Shulman, G.I., Magnuson, M.A., and Kahn, C.R. (2000). Mol. Cell. 6, 87-97.

Miller, S.P., Anand, G.R., Karschnia, E.J., Bell, G.I., LaPorte, D.C., and Lange, A.J. (1999). Diabetes 48, 1645-1651.

Moates, J.M., Shelton, K.D., and Magnuson, M.A. (1996). Mol. Endocrinol. 10, 723-731.

Moates, J.M., Postic, C., Decaux, J.-F., Girard, J., and Magnuson, M.A. (1997). Genomics 45, 185-193.

Nagy, A. (2000). Genesis 26, 99-109.

Niswender, K.D., Postic, C., Jetton, T.L., Bennet, B., Piston, D., Efrat, S., and Magnuson, M.A. (1997a). J. Biol. Chem. 272, 22564-22569.

Niswender, K.D., Shiota, M., Postic, C., Cherrington, A.D., and Magnuson, M.A. (1997b). J. Biol. Chem. 272, 22570-22572.

O'Doherty, R.M., Lehman, D.L., Seoane, J., Gomez-Foix, A.M., Guinovart, J.J., and Newgard, C.B. (1996). J. Biol. Chem. 271, 20524-20530.

O'Doherty, R.M., Lehman, D.L., Telemaque-Potts, S., and Newgard, C.B. (1999). Diabetes 48, 2022-2027.

Pilkis, S.J., Weber, I.T., Harrison, R.W., and Bell, G.I. (1994). J. Biol. Chem. 69, 1925-1928.

Pinkert, C.A., Ornitz, D.M., Brinster, R.L., and Palmiter, R.D. (1987). Genes Devel. 3, 268-276.

Piston, D.W., Knobel, S.M., Postic, C., Shelton, K.D., and Magnuson, M.A. (1999). J. Biol. Chem. 274, 1000-1004.

Pontoglio, M., Sreenan, S., Roe, M., Pugh, W., Ostrega, D., Doyen, A., Pick, A.J., Baldwin, A., Velho, G., Froguel, P., Levisetti, M., Bonnerweir, S., Bell, G.I., Yaniv, M., and Polonsky, KS. (1998). J. Clin. Invest. 101, 2215-2222.

Postic, C., and Magnuson, M.A. (2000a). Genesis 26, 149-150.

Postic, C., and Magnuson, M.A. (2000b). In "Molecular Pathogenesis of MODYs" (F.M. Matschinsky and M.A. Magnuson, eds.), Frontiers in Diabetes, vol. 15, pp 293-298. Karger, Basel, Switzerland.

Postic, C., and Magnuson, M.A. (2001). In "Molecular Basis of Endocrine Pancreas Development and Function"' (M.A. Hussain and J.F. Habener, eds.). Kluwer Academic Publishers, Norwell, Mass., in press.

Postic, C., Niswender, K.D., Decaux, J.-F., Parsa, R., Shelton, K.D., Gouhot, B., Pettepher, C.C., Granner, D.K., Girard, J., and Magnuson, M.A. (1995). Genomics 29, 740-750.

Postic, C., Shiota, M., Niswender, K.D., Jetton, T.L., Chen, Y., Moates, J.M., Shelton, K.D., Lindner, J., Cherrington, A.D., and Magnuson, M.A. (1999). J. Biol. Chem. 274, 305-315.

Rencurel, F., Waeber, G., Antoine, B., Rocchiccioli, F., Maulard, P., Girard, J., and Leturque, A. (1996). Biochem. J. 14, 903-909.

Roncero, I., Alvarez, E., Vazquez, P., and Blazquez, E. (2000). J. Neurochem. 74, 1848-1856.

Rossetti, L., Chen, W., Hu, M.Z., Hawkins, M., Barzilai, N., and Efrat, S. (1997). Am. J. Physiol. 36, E743-E750.

Sauer, B. (1993). Meth. Enzymol. 225, 890-900.

Sauer, B., and Henderson, N. (1988). Proc. Natl. Acad. Sci. U.S.A. 85, 5166-5170.

Sebastian, S., Horton, J.D., and Wilson, J. (2000). Biochem. Biophys. Res. Comm. 270, 886-891. 
Seoane, J., Gomez-Foix, A.M., O’Doherty, R.M., Gomez-Ara, C., Newgard, C.B., and Guinovart, J.J. (1996). J. Biol. Chem. 271, 23756-23760.

Shelton, K.D., Franklin, A., Khoor, A., Beechem, J., and Magnuson, M.A. (1992). Mol. Cell Biol. 12, 4578-4589.

Shih, H., and Towle, H.C. (1994). J. Biol. Chem. 269, 9380-9387

Shiota, C., Coffey, J., Grimsby, J., Grippo, J.F., and Magnuson, M.A. (1999). J. Biol. Chem. 274, 37125-37130.

Shiota, M., Postic, C., Fujimoto, Y., Jetton, T.L., Dixon, K., Pan, D., Grimsby, J., Grippo, J.F., Magnuson, M.A., and Cherrington, A.D. (2001). Diabetes, in press.

Soriano, P. (1999). Nature Genet. 21, 70-71.

Sreenan, S.K., Cockburn, B.N., Baldwin, A.C., Ostrega, D.M., Levisetti, M., Grupe, A., Bell, G.I., Stewart, T.A., Roe, M.W., and Polonsky, K.S. (1998). Diabetes 47, 1881-1888.

Stoffers, D.A., Ferrer, J., Clarke, W.L., and Habener, J.F. (1997a). Nature Genet. 17, 138-139.

Stoffers, D.A., Zinkin, N.T., Stanojevic, V., Clarke, W.L., and Habener, J.F. (1997b). Nature Genet. 15, 106-110.

Sturis, J., Kurland, I.J., Byrne, M.M., Mosekilde, E., Froguel, P., Pilkis, S.J., Bell, G.I., and Polonsky, K.S. (1994). Diabetes 43, 718-723.

Sweet, I.R., Li, G., Najafi, H., Berner, D., and Matschskiny, F.M. (1996). Am. J. Physiol. 271, E606-E625.

Tappy, L., Dussoix, P., Iynedjian, P., Henry, S., Schneiter, P., Zahnd, G., Jequier, E., and Philippe, J. (1997). Diabetes 46, 204-208.

Terauchi, Y., Sakura, H., Yasuda, K., Iwamoto, K., Takahashi, N., Ito, K., Kasai, H., Susuki, H., Ueda, O., Kamada, N., Jishage, K., Komeda, K., Noda, M., Kanazawa, N., Tanigushi, S., Miwa, I, Akanuma, Y., Kodama, T., Yasaki, Y., and Kadowaki, T. (1995). J. Biol. Chem. 270, 3025330256.

Thomas, P.M., Cote, G.J., Wohllk, N., Haddad, B., Matthew, P.M., Rabl, W., Aguilar-Bryan, L., Gagel, R.F., and Bryan, J. (1995). Science 268, 426-429.

Vandercarmmen, A., and Van Schaftingen, E. (1990). Eur. J. Biochem. 191, 483-489.

Van Schaftingen, E. (1989). Eur. J. Biochem. 179, 179-184.

Vaulont, S., and Kahn, A. (1994). FASEB J. 8, 28-35.

Velho, G., Petersen, K.F., Perseghin, G., Hwang, J.-H., Rothman, D.L., Pueyo, M.E, Cline, G.W., Froguel, P., and Shulman, G.I. (1996). J. Clin. Invest. 98, 1755-1761.

Velho, G., Blanche, H., Vaxillaire, M., Bellanne-Chantelot, C., Pardini, V.C., Timsit, J., Passa, P., Deschamps, I., Robert, J.-J., Weber, I.T., Marotta, D., Pilkis, S.J., Lipkind, G.M., Bell, G.I., and Froguel, P. (1997). Diabetologia 40, 217-224.

Vionnet, N., Stoffel, M., Takeda, J., Yasuda, K., Bell, G.I., Zouali, H., Sesage, S., Lesage, S., Velho, G., Iris, F., Passa, P., Froguel, P., and Cohen, D. (1992). Nature 356, 721-722.

Wang, H., and Iynedjian, P.B. (1997). Proc. Natl. Acad. Sci. U.S.A. 94, 4372-4377.

Weinhouse, S. (1976). Curr. Top. Cell Reg. 11, 1-50.

Wilson, J.E. (1995). Rev. Physiol. Biochem. Pharmacol. 126, 65-198.

Yamagata, K., Furuta, H., Oda, N., Kaisaki, P.J., Menzel, S., Cox, N.J., Fajans, S.S., Signorini, S., Stoffel, M., and Bell, G.I. (1996a). Nature 384, 458-460.

Yamagata, K., Oda, N., Kaisaki, P.J., Menzel, S., Furuta, H., Vaxillaire, M., Southam, L., Cox, R.D., Lathrop, G.M., Boriraj, V.V., Chen, X., Cox, N.J., Y., O., Yano, H., Le Beau, M.M., Yamada, S., Nishigori, H., Takeda, J., Fajans, S.S., Hattersley, A.T., Iwasaki, N., Hansen, T., Pedersen, O., Polonsky, K.S., Bell, G.I., et al. (1996b). Nature 384, 455-458. 
